\title{
LA PERSONA VISTA DESDE EMMANUEL MOUNIER Y SU REPERCUSIÓN EN LA MISIÓN EDUCATIVA
}

\section{The person from Emmanuel Mounier's view and its impact on the educational mission}

\author{
Judith LeÓn Guevara \\ Fundación Universitaria Miraflores. Bogotá \\ Correo-e: judithleonz2@yahoo.es \\ Recepción: 20 de mayo de 2014 \\ Envío a informantes: 28 de mayo de 2014 \\ Aceptación definitiva: 26 de enero de 2015 \\ Biblid. [0214-3402 (20I5) (II época) n. ${ }^{\circ}$ 2I; 177-192]
}

Resumen: Artículo de reflexión crítica, en el que se parte de describir los conceptos de personalismo y persona, para adentrarse luego en el análisis de los vínculos entre el personalismo de Mounier y su repercusión en la misión educativa, evidenciando toma de postura sobre el compromiso humano con la formación y mejora de la persona.

Palabras clave: personalismo; persona; valores; misión educativa; formación.

Aвstract: Article of critical reflection, that begins with the description of the concepts of personal reference and person, in order to go deeply into the analysis of the links between Mounier's personal reference and it's impact on the educational mission, putting into evidence the position about the human commitment with the person's formation and improvement.

KEY WORDS: personal reference; person; values; educational mission; formation.

El primer acto de mi iniciación a la vida personal es tener conciencia de mi vida anónima. El primer paso, correlativo, de mi iniciación a la vida comunitaria, es tener conciencia de mi vida indiferente: indiferente para los demás, porque ella está indiferenciada de los demás. Estamos aquí por debajo del umbral en que comienza la vida solidaria de la persona y de la comunidad (Mounier, 1995: 45).

... l'univers personnel définit l'univers moral et coincide avec lui... Être, c'est aimer, avons-nous dit. Mais être, c'est aussi s'affirmer (Mounier, 1995: 63).

I MOUnIER: «El universo personal define al universo moral y coincide con él... Ser es amar, hemos dicho. Pero ser es también afirmarse». 


\section{El personalismo}

4

L MOVIMIENTO PERSONALISTA SURGIÓ EN LA PRIMERA MITAD de nuestro siglo Xx, como respuesta a los interrogantes que la situación crítica de ese momento planteaba a muchos que no querían resignarse ante el fracaso de la civilización occidental, ni adaptarse y asimilarse al momento para sacar en forma egoísta el mejor provecho, sino que, por el contrario, querían comprometerse en una acción decidida que ofreciera una alternativa y una solución verdaderamente humanas.

El personalismo es así un movimiento amplio en el cual pueden incluirse diversos autores corrientes y posiciones que buscan, por encima de todo, la solución «humana» a los graves problemas que afronta el hombre actual. Pero en sentido estricto, el personalismo vino a significar la perspectiva generada a partir de la obra de Emmanuel Mounier (1905-1950) y del grupo que, junto con él, publicaba la revista ESPRIT, órgano que servía para expresar sus concepciones y para dar a conocer sus posiciones.

Después de la muerte de Mounier y a través de muchas vicisitudes la perspectiva personalista se fue enriqueciendo con otros aportes y se fue constituyendo en la fuente de inspiración de enfoques pedagógicos que, asumiendo y contemplando los principios personalistas, intentan intervenir y orientar las diversas acciones del hombre actual en la familia, en la educación, en la acción política, económica, cultural, etc.

Así lo vislumbró el mismo Mounier, quien en su Manifiesto al servicio del personalismo escribió:

Llamamos personalista a toda doctrina y a toda civilización que afirma el primado de la persona humana sobre las necesidades materiales y sobre los mecanismos colectivos que sostienen su desarrollo... El personalismo no anuncia, pues, la creación de una escuela, la apertura de una capilla, la invención de un sistema cerrado. Testimonia una convergencia de voluntades, y se pone a su servicio, sin afectar su diversidad, para buscar los medios de pensar eficazmente sobre la historia (Mounier, 1995: 9).

Desde esta perspectiva, el personalismo se presentó también como un severo diagnóstico de la situación social, que conduce a establecer las siguientes conclusiones:

I. La crisis de la sociedad, con sus graves efectos en el orden económico, político, familiar, existencial, etc., es fundamentalmente una crisis espiritual, es decir, una crisis de valores.

2. Esta crisis no es simplemente circunstancial, sino estructural y, además, una crisis que se ha incrustado en las mismas instituciones, en el mismo sistema social imperante; que se acepta como un hecho necesario y, lo más grave, que muchos no reconocen como «crisis», sino como una característica propia de la sociedad y del hombre de todos los tiempos.

3. Este desorden establecido no es otra cosa que una situación de deshumanización, de alienación, de despersonalización. El hombre ha perdido su rumbo, los valores humanos han sido remplazados por valores materiales, como el dinero, el lujo, el placer, el tener. El hombre ha sido convertido en instrumento, en cosa, en objeto. La humanidad está amenazada por su autodestrucción y hoy nos preguntamos, a nivel personal, familiar, social, si podremos sobrevivir, si tiene sentido que nuevos hombres nazcan frente a un futuro incierto; nos 
preguntamos cuáles son los costos que debemos pagar para poder sobrevivir y quiénes son los privilegiados que tienen ese derecho a costa de los demás.

4. La causa y consecuencia a la vez de ese «desorden establecido» consistente en el espíritu burgués que, surgido en los albores de la Edad Moderna (siglos XVII y xVIII), se ha generalizado y absolutizado hasta tal punto que es lo único que se reconoce como válido y sostiene todos los sistemas sociopolíticos dominantes de Occidente y de Oriente.

5. Ante ese «desorden establecido» se pueden adoptar diversas opciones:

a. Defenderlo como el «mejor de los mundos posibles» y reprimir todo intento de crítica, de cuestionamiento, de cambio, calificando tales actitudes de «subversivas», anárquicas, productos del resentimiento social y de la envidia, atentadoras del «orden».

b. Reconocer que tiene sus fallas porque «lo humano es imperfecto» y aceptar que nunca lograremos la felicidad completa, ni darle gusto a todos ni ofrecer igualdad de condiciones para todos y, en consecuencia, tratar de hacer las cosas cada vez mejor, mejorar el sistema, procurar que al menos todos tengan «igualdad de oportunidades», que exista «igualdad de derechos», pero todo ello dentro del «sistema» que es el único que ha existido y que existirá.

c. Tomar una posición crítica, pero al mismo tiempo lúcida y fundada, que lleve a reconocer las causas y circunstancias, los mecanismos y procesos del "desorden establecido", a fin de buscar alternativas válidas y reales y, sobre todo, comprometerse en una acción decidida que trasforme el desorden establecido e instaure un verdadero orden, genere el surgimiento de un nuevo hombre, de una nueva sociedad, de una nueva civilización.

El personalismo nos mueve a adoptar esta tercera actitud honesta y coherente, una «revolución personalista y comunitaria» que vaya creando las condiciones de una nueva civilización, de una nueva sociedad, de un nuevo hombre.

Ahora bien, la «revolución personalista y comunitaria» que propone el personalismo tiene varias características que la identifican y que sirven de criterios a la hora de escoger los medios, las estrategias, las técnicas y las tácticas para su realización:

I. La primera característica es reconocer el valor absoluto de la dignidad de la persona. El valor y dignidad de persona humana es algo inalienable de todo ser humano, independiente de su condición social, sus creencias, su raza, su sexo, etc.

2. La persona humana implica una dimensión comunitaria que le es esencial; todo el hombre y todos los hombres son personas con igual valor y dignidad; por ello, la tras-formación de la sociedad debe estar orientada a lograr la vida comunitaria. Se trata de asumir e involucrarnos en una dinámica histórica en un proceso de personalización y de comunitariedad.

3. La revolución personalista y comunitaria no es sólo una acción histórica que debe emprenderse y organizarse, que exige lucha, sacrificios, entrega, compromiso, sino que es, ante todo, "un estilo de vida», una opción radical, una manera de ver, de juzgar, de imaginar y de actuar en todos los momentos de la existencia; una manera de vivir las relaciones humanas como relaciones interpersonales, es decir, de valorarme y valorar, de tratarme y tratar a los demás como personas. 
En conclusión, el personalismo para Mounier, más que una teoría o una doctrina, es una vida; es una postura personal; es una ética.

\section{Valores del universo personal}

El personalismo, hemos dicho, es una toma de posición a favor del hombre como persona y una afirmación radical de la primacía de la persona humana sobre cualquier otra cosa. Pero, ¿qué se entiende por «persona» y qué implicaciones se siguen de tal concepción? Una persona es indefinible porque no es una cosa, un objeto; sólo podemos tener una vivencia de lo que es ser persona en una relación interpersonal. Más bien podríamos decir lo que no es persona: el hombre no es persona cuando es tratado como un objeto, como cosa; cuando es manipulado, utilizado, instrumentalizado; no es persona cuando es masificado, estandarizado, reducido al anonimato; cuando es considerado sólo en sus aspectos biológicos, orgánicos: como un simple animal un poco más desarrollado. Ser y poder ser uno mismo, ser y poder llegar a ser auténticamente hombres; esto es lo que significa ser persona.

En tal sentido, y ante la imposibilidad de dar una definición de persona, lo que el personalismo nos ofrece es un marco de referencia que nos permita considerar al hombre como ser personal. Dicho marco de referencia consiste en una descripción de aquellas características y dimensiones que constituyen el universo personal. Algo así fue lo que nos presentó Mounier en la siguiente afirmación con la cual él quiso aproximarse a esa realidad. Una persona, afirma Mounier

es un ser espiritual constituido como tal por una forma de subsistencia y de independencia en su ser; mantiene esta subsistencia mediante su adhesión a una jerarquía de valores libremente adoptados, asimilados y vividos en un compromiso responsable y en una constante conversión; unifica así toda su actividad en la libertad y desarrolla por añadidura impulsos de actos creadores, la singularidad de su vocación (Mounier, 1995: 42).

Persona es, ante todo, una forma de ser. Persona es una vocación y un compromiso. Persona es la adopción y el vivir una determinada jerarquía de valores. Persona es aquello que unifica toda nuestra acción y nuestra vida. El hombre es un ser que se hace persona. Y se hace persona cuando logra desarrollar las dimensiones constitutivas de su ser.

Mounier comparte la centralidad e importancia del concepto de persona con la tradición cristiana, aunque en la definición anterior no se nombre a Dios como fundamento y constituyente de la realidad personal. Constatada la ausencia de Dios en la definición de persona, cabría preguntarse por el significado de «ser espiritual» de que habla Mounier. Lo «espiritual» es la primacía de lo vital sobre lo material, de los valores de la cultura, de los valores accesibles a todos, como el amor, la bondad, la caridad. Cuando Mounier habla de espiritualidad se está refiriendo a un ser con vocación de eternidad, de perseverancia, pero se siente el vacío de que no fundamenta su concepto de persona desde Dios.

\section{La persona vista desde el pensamiento filosófico}

Para ampliar la visión de persona que proyecta Mounier en su Manifiesto, es necesario rastrear el concepto mismo de persona, que define lo específico del hombre; para ello nos adentraremos en el campo de la historia filosófica. 
En primer lugar es preciso reconocer, que el concepto «persona» es un concepto nodal, que abarca su corporeidad, su afectividad, su lenguaje, su espiritualidad. La persona abarca, recoge, unifica e integra esa pluralidad de aspectos. Pero la persona también es «respuesta» a un proyecto inacabado, a una llamada que se le hace para que busque su plena realización como ser.

Pero, ¿qué expresamos cuando decimos que alguien es persona? La pregunta tiene una serie de significados y para esclarecerlos es preciso que acudamos a la historia de la filosofía.

Para la filosofía griega, el concepto es extraño; los griegos reconocen al hombre como ciudadano; de ahí que para ellos, según Aristóteles (384-322 a. C.), el Estado es siempre anterior a la familia y a cada individuo en particular, porque el todo es antes que la parte, y por eso justifica la esclavitud, la superioridad del hombre sobre la mujer y la de ciertos pueblos y razas sobre otros (Aristóteles, 2004). Es la fenomenalización de algo universal; el hombre es un simple «algo», entre lo ideal y lo abstracto.

El término «persona» es de origen latino y el concepto representa un papel o rol, es una máscara que expresa y va mostrando un carácter, un personaje, una persona. Este término designa lo que es común a todos los hombres y esto viene dado por la razón particular de cada uno: carácter, temperamento, capacidades, lo hereditario y lo que vamos asimilando en los diferentes contextos en que tengamos que vivir, el peso de las elecciones que vamos haciendo en la vida. Posteriormente y ya en la Roma imperial nace el nuevo concepto jurídico de persona; la persona es sujeto de deberes y de derechos. Nace el sujeto jurídico, del cual derivará el sujeto moral.

Avanzando en la historia y adentrándonos en la era cristiana, observamos que uno de los grandes aportes del cristianismo al mundo es el concepto de persona. Mounier (1980), en El Personalismo (obras completas III, pp. 454-455), afirma «Que el sentido de la persona queda embrionario en la Antigüedad hasta los albores de la era cristiana».

El cristianismo depara unas coordenadas de pensamiento que hacen posible el concepto de persona. Mientras la filosofía griega acentúa lo universal, lo ideal, lo abstracto del hombre, el cristianismo pone su acento en lo singular, lo individual, lo concreto de la persona. El valor absoluto de la persona es una conquista del pensamiento cristiano.

Para un creyente, en la Biblia, aparece la persona como «creada a imagen y semejanza de Dios» (Gn I,27); y en el Nuevo Testamento, Jesús radicaliza el origen y la meta del hombre: «vosotros sed perfectos como vuestro Padre Celestial es perfecto» (Mt. 5,48). Es a través del Evangelio que llegaron los primeros cristianos a experimentar y luego a predicar cómo la persona es algo sagrado, un fin en sí mismo, sujeto de derechos inalienables, libre y por lo tanto responsable; un ser social que debe entrar en relaciones de igualdad, fraternidad y solidaridad (Lc 6,I-II,33-36; I2,I-7).

Otro aporte también propio del cristianismo, según Hegel (2006), es el concepto de libertad. El individuo como tal tiene un valor infinito en relación absoluta con Dios y, por tanto, determinado a la suprema libertad.

Como vemos, a lo largo de la historia, muchas escuelas de pensamiento y autores han profundizado el concepto de persona; algunos han puesto el acento en lo social, jurídico y filosófico; otros en el aspecto de su singularidad y libertad; en la razón de su ser, o de su existencia, de su naturaleza racional. La concepción aristotélica-tomista evidencia sus supuestos ónticos de independencia, racionalidad e individualidad. 
San Agustín (354-430) designa al hombre como ser «singular e individual»; cada hombre es una persona, utiliza el término en sentido filosófico y establece con claridad el concepto, como una fusión de autonomía y relación; en sí autónoma, pero, a la vez, con un profundo sentido de relación.

San Buenaventura (I2I8-I274) explica elementos constitutivos del ser persona; su capacidad de relación, como elemento esencial, por eso expresa con toda claridad que ser persona es ser en relación y esto en un triple sentido; un hombre en relación con toda la realidad, dirigido hacia el otro. En segundo lugar, un ser en relación con Dios; un ser, en tercer lugar, intersubjetivo, en relación con los otros.

La Escuela Franciscana pone el énfasis en la importancia de la voluntad en el ser persona con la capacidad que tiene para obrar el bien. La Tomista, en la razón, con la capacidad para el encuentro de la Verdad.

Estas escuelas definen la persona en términos éticos, dan relevancia a su dignidad, al compromiso ineludible que tiene para desenvolverse como proyecto en el mundo, mediada por su libertad. De ahí, la necesidad de una formación de la conciencia crítica, de anclarse en convicciones profundas para que su conducta sea el resultado de la formación de su carácter moral.

En la modernidad, con Descartes se abre camino un nuevo concepto de persona. Descartes (2003) define la persona con referencia a la capacidad de autoconciencia; puede ser él mismo; es una realidad auténtica porque se piensa así mismo; "pienso, luego soy». Es John Locke (1980) (1632-1704) quien a través de sus análisis, expuestos en su obra: Ensayo sobre el entendimiento bumano, II, vol. I, saca las consecuencias para el concepto de persona, guardando el término para lo puramente mental; lo que la diferencia de los animales supuestos ónticos de independencia, racionalidad e individualidad. La libertad muestra el lado práctico de la racionalidad. Es la conciencia de sí misma la que determina: «Es un ser pensante e inteligente, provisto de razón y de reflexión, y que puede considerarse a sí mismo como una misma cosa pensante en diferentes tiempos y lugares, lo que tan solo hace porque tiene conciencia, porque es algo inseparable del pensamiento, y que para mí le es esencial» (John Locke, i980). Al explicar que «el sí mismo depende de la conciencia y no de la sustancia», otros aspectos como la corporalidad y relación no los evidencia, aunque se pueden deducir cuando destaca el carácter moral, por ende, jurídico de la persona. Si el concepto de persona en el Medievo era teológico, en el modernismo es de raíz ética.

El Idealismo alemán, de manera especial en Kant (I724-1804) y Hegel (2006) (I770I83i), parte también del aspecto de la conciencia, no de la sustancia. "Toda persona se da en dos sentidos distintos: como determinada y como universal». La importancia de esta abstracción pone de manifiesto la potencialidad de prescindir de las particularidades para mostrar que el valor de la persona radica en el hecho de ser un individuo humano; es alguien determinado; una persona específica que con sentido de identidad puede expresar: "Yo soy», experimentándose como existente, dirigiendo su pensamiento a sí mismo; mostrándose como meta, con capacidad para autorrealizarse; es autónoma, por consiguiente «responsable» moralmente alguien ante la ley, la conciencia.

Max Scheler (1874-1928), citado por Pintor y Ramos, entra acentuando el carácter de la persona en su capacidad de responder de algo, de su acción ante la forma concreta en que existe el espíritu en el hombre. Dice: «Denominaremos persona al centro activo en el que el espíritu se manifiesta en las esferas del ser infinito; la persona es la 
forma de existencia esencialmente necesaria y única del espíritu en cuanto se trata de un espíritu concreto» (Pintor y Ramos, 1986: 285-305).

Todos estos autores, así como otros a los que no hemos hecho alusión, ponen el acento en algunos aspectos del ser persona. Mounier trata de verla en la óptica de ese ser dotado de: Singularidad, Autonomía, Apertura y Trascendencia, dando aportes para que el educador busque orientar su misión educativa de manera creativa y responsable, respondiendo al porqué y para qué de la existencia.

En la actualidad hay varios autores dedicados a preguntarse sobre la persona y hacen un recorrido a través de la historia, analizando lo que muchos han dicho y escrito al respecto. Uno, muy valioso por ser contemporáneo y muy profundo en sus investigaciones, es Tziizis (I999), quien escribe un tratado sobre Quién es la Persona? (Qu' est-ce que la personne?), llegando hasta la postmodernidad en el análisis de varios escritores y exponiendo su propio pensamiento y convicción. Para él, el hombre no puede ser estudiado ni analizado sino a través de su determinación ontológica; lleva en sí mismo la imagen de Dios; es una existencia llena de contenido substancial. El hombre-persona está creado a imagen de Dios («Hipóstasis divino»), con una interioridad dotada de una densidad tal porque participa de la esencia divina; está definido en función de su identidad; lleva en su ser los gérmenes de las cualidades de Dios, tales como la justicia y el amor (ágape), los cuales sostienen los privilegios de su dignidad humana. Es gracias a la Hipóstasis del Hijo hecho Carne como el hombre recibe toda la luz sobre la Trascendencia que le confiere su dignidad.

Todos estos autores ponen el acento en algunos aspectos del ser persona. Vamos a tratar de verla en la óptica de ese ser dotado de: Singularidad, Autonomía, Apertura y Trascendencia, como lo hiciera Mounier y que he investigado y explicitado a través de mis obras, dando aportes para que el educador busque orientar su misión educativa de manera creativa y responsable.

Etre personnel, se singulariser...Un original, dit-on encore d'une personalitè marquée. ... La personne immerge dans la nature; la personne trascende la nature.-L'homme est un corps au même titre qu'il est esprit, tout entier «corps» et tout entier «esprit»... Elle se fonde sur une série d'actes originaux qui n'ont leur equivalent nulle part ailleurs dans l'univers: - La personne est une existence capable de:

I. Sortir de soi. 2. Comprendre. 3. Prendre sur soi, assumer le destin, la peine, la joie, la tâche d'autrui... 4. Donner. 5. Être fidèle.

La fidélité personnelle est une fidélité créatrice (Mounier, I999: 15, 17, 34 -35, 57)².

En la afirmación que citamos de Mounier se insinúan algunas de esas «notas»o dimensiones que constituyen a la persona y que son: singularidad, autonomía, apertura y trascendencia.

Ser singular implica que «todos somos uno, no obstante, cada uno de nosotros es una entidad única e irrepetible» (Fromm, 1972: 64), que al darse una sola vez y ser consciente de esa realidad, "al contrario del animal, no solamente vive, sino existe y su existencia es histórica, se da en el mundo que cada uno crea y transforma incesantemente» (Freire, I971: 62).

Mounier (1995): «Ser personal, singularizarse... se dice también de una personalidad bien definida que es un original (p. 57). La persona está inmersa en la naturaleza pero la trasciende (p. 17). El hombre así como ese espíritu es también un cuerpo; totalmente "cuerpo» y totalmente «espíritu» (p. Is). La persona se funda en una serie de actos originales que no tienen su equivalencia en ninguna otra parte dentro del universo: I. Salir de sí. 2. Comprender. 3. Tomar sobre sí, asumir el destino, la pena, la alegría, la tarea de los otros, «sentir dolor en el pecho». 4. Dar. 5. Ser fiel. La fidelidad personal es una fidelidad creadora (pp. 34-35)». 
Al comenzar por la pregunta fundamental nos referimos al hombre como Unidad en la diversidad: espiritual y material: «Un espíritu encarnado, una inteligencia, una voluntad encarnadas, una afirmación de amor del Absoluto» (Doncell, I970: 452). Porque es espíritu, tiene conciencia de su conexión con el cosmos, trascendiéndolo a la vez, porque su horizonte es infinito en orden al querer y al conocer, aunque sus posibilidades reales de elección son limitadas. Así, la persona es un sujeto particular y autónomo; que se posee a sí mismo, siendo el centro de su ser y de su hacer, realizándose con libertad y conciencia. Al tener esta autonomía, de ser singular, es persona (Coreth, 1964: 37I).

El hombre está básicamente individualizado por la relación de su espíritu con la materia cuantificada y secundariamente por su historia personal, escrita a través de sus decisiones libres. No solo siente; tiene inteligencia, razón y voluntad y las demás facultades que constituyen la unidad que llamamos persona. Es capaz de sentir y de sentirse; por su inteligencia, tiene capacidad para intuir la verdad y por la razón, para actuar conforme a la verdad intuida.

Al entender la verdad, no solo es un «portador de valores», sino él mismo intrínsecamente es un valor que expresará como tal, a través de sus actos humanos. Aunque existente, se irá haciendo a sí mismo; no tiene otra tarea más importante que afirmarse como ser racional, inteligente y libre.

Detengámonos un momento en el solo aspecto de su poder cuerpo-mente, por la complejidad del cerebro, al servicio de la inteligencia. Es todo un reto para el educador en la orientación para producir conocimiento de la mejor manera, poniendo en juego y consonancia: cuerpo, cerebro-mente; es «aprender cómo aprender», percibir lo que pasa abi adentro y afirmar el poder de la conciencia.

El cerebro humano es el responsable de cómo componía música Beethoven y pintaba Van Gogh, de la creación de millones de innovaciones. Se compara a una jungla feroz de cien mil millones de células nerviosas o neuronas. Cada célula nerviosa tiene un axón y hasta cien mil dendritas. El continuar aprendiendo expande las redes neuronales del cerebro, creando conexiones siempre más abundantes. La alimentación también juega un papel importante en la potenciación del cerebro (Ostrander, 1996: I90 y ss.) Aspectos, son éstos, de la neurociencia que debe saber el maestro para orientar procesos de diferente índole, de manera integral.

Las conexiones guían nuestros cuerpos y conductas a la vez que cada uno de nuestros pensamientos y cada una de nuestras acciones.

El reto, la complejidad, la novedad: estas son cosas que encienden ambos hemisferios, se apoderan de tu atención y conducen a un aprendizaje y memoria muy superiores (Ostrander, 1996: 18I).

Es el desarrollo de la Originalidad que viene dada por la dinámica de la Singularidad y nos da la oportunidad para crear e innovar permanentemente.

La familia tuvo, hace unas cuantas décadas, lo mismo que la escuela una carga social importante en la formación integral de la persona. Poco a poco se ha ido reduciendo el espacio prácticamente para la administración de saberes, sin tener en cuenta la circulación de otros muchos que están en manos de los niños, jóvenes y adolescentes y que son tomados directamente por ellos de los medios audiovisuales, la Internet. La tecnología viene desplazando a la escuela como lugar de socialización y ésta pretende ponerse al día llenándose de computadores, olvidando que tan solo son medios pero no auténticas mediaciones para lograr el fortalecimiento total del estudiante. 
Al profundizar e interiorizar la filosofía de Mounier sobre la persona nos encontramos, maestros y estudiantes y lo expreso por experiencia, frente a una exigencia: producir una transformación en nuestro interior; reorganizar intrínsecamente nuestra vida, nuestra capacidad de pensar, de vivir emociones, de llegar a ser, desde lo elemental, una persona para los demás. Es plantearse todo un proyecto para vivir profunda e intensamente el día a día en la «escuela de la existencia» (Cury, 2002: I43 y ss.), «aprendiendo a aprender» desde lo que se aprehende y descubre para producir conocimiento, empezando por el deber-ser, gran desafío frente a algunos paradigmas que se nos presentan y que van en contra de una auténtica personalización y liberación. Tener actitud de aprendiz frente a la existencia hace bien a la salud síquica y a la salud del cerebro porque se expanden las redes neuronales, originando conexiones todavía más abundantes, haciendo posible la innovación creativa. De ahí, que una de las tareas bien importantes del ser maestro es enseñar a pensar.

Hoy se imponen y, de hecho, hay nuevos modos de producción de conocimiento. Me permito citar una alternativa, a manera de ejemplo, que como situación concreta tiene trabajo investigativo de base y una matriz epistémica que se constituye en el trasfondo existencial en el cual se mueven el estudiante y el docente, siendo fuente que origina y orienta el modo general de conocer, asignando significados a los hechos, a los eventos y al objeto de estudio en sí, por la capacidad y forma de simbolizar la realidad: LAS UDPROCO - Unidades de Producción de Conocimiento ${ }^{3}$.

Como mediación pedagógica crea las condiciones para acercar al sujeto que conoce con los objetos de estudio, con las demás personas involucradas en el evento, poniéndolos en relación dialógica. Tanto el docente como los estudiantes van encontrando de manera explícita las características esenciales de su ser inteligente, creativo, con capacidad para decidir, transformar y relacionarse con los otros, con la comunidad en la cual se encuentran insertos.

La investigación al respecto de la uDPROco como mediación pedagógica está desarrollando conocimiento en torno a las implicaciones científicas y axiológicas de la educación y está demostrando que es un fuerte apoyo para la recuperación del sentido de la existencia humana, de sus posibilidades como tal y de la cohesión social, dando sentido trascendente a la búsqueda del conocimiento con el propósito de intervenir la realidad, crear nuevas cosmovisiones, nuevas actitudes, conocimientos y prácticas, dado el clima en el cual se pueden desarrollar, libre de represión y abierto a la interdisciplinariedad.

En este desarrollo del conocimiento, la creatividad y el rigor se dan espontáneamente cuando la persona sabe a dónde va; cuando se motiva por lo que debe conquistar y encuentra directrices claras, amplias y creativas en sí mismas, capaces de suscitar búsquedas, reflexión e información y lo bastante claras como para orientarlas.

La creatividad es algo que surge de la esencia misma del hombre y fundamenta su tendencia de llegar a ser lo que potencialmente es. La vida creadora empieza a surgir en su relación con la naturaleza que le interpela, le sugiere, le cuestiona y le induce a relacionar, idear, proyectar... haciendo personal lo que es puramente objetivo (León, 2000: 45 y ss.). El hombre es esa maravilla, la única, que posee la memoria que testimonia su paso por el mundo como individualidad obrante. Solo él aspira a crear inventando,

LeÓn Guevara (200I-2007). El Trabajo investigativo evidenció que la «Unidad de Producción de Conocimiento", como mediación pedagógica, posibilita el desarrollo de potencialidades referidas al pensamiento científico, creador y al desarrollo moral e intelectual autónomo. Crea condiciones y ambientes educativos para el aprendizaje personal y cooperativo con sentido personalizante y liberador. 
innovando, para permanecer en la posteridad, desafiando el tiempo; sabe bien que está en un devenir siempre en movimiento que guarda celosamente los secretos del ser al abrigo del saber humano (Tzitzis, I999: 7).

Encauzar para emplear el pensamiento lógico, verbal y lineal (León, 200I: I7I) que se sitúa en el hemisferio cerebral izquierdo, interconectándolo con el imaginativo, metafórico, sintetizador e intuitivo, propio del hemisferio cerebral derecho, es orientar al estudiante a desarrollar en alto grado la posibilidad de creatividad.

La calidad de la educación hoy en día está íntimamente asociada con la práctica de la investigación. El interés de los docentes por los métodos no expositivos y dentro de éstos por la docencia investigativa convoca a los profesores de los cuatro niveles: preescolar, básica y media, superior en pregrado y postgrado, a conocer y discutir el tema de la relación entre la investigación y la enseñanza. Desde la función pedagógica centramos la atención en la investigación formativa.

El futuro, al proyectarse desde el presente, exige la puesta en movimiento de la libertad creadora del hombre. Observar, conocer, admirar, respetar, amar y vibrar son pasos extraordinarios en el direccionamiento del proceso de producción de conocimiento creativo (León, 2000: 60 y ss.).

Un proceso educativo, teniendo en cuenta las características esenciales de la persona, ha de situarnos en esta era sistemática ${ }^{4}$ que se abrió paso para trabajar en función de los sujetos, teniendo en cuenta la interdependencia de los mismos y las relaciones que deben mantener en diferentes campos, poniendo en juego todas sus potencialidades.

Para poder vivir en el siglo xxi se necesita dotarnos aún más como educadores de tal modo que se transfiera el empowerment (empoderamiento) al estudiante, en los campos del dominio personal, la creatividad e innovación, el trabajo en equipo, la sistematización de cuanto se proyecte y realice, teniendo en cuenta la interdisciplinariedad y transdisciplinariedad, según los casos.

Los estudiantes irán incorporando en su mente y comportamiento la necesidad de actuar siempre con mente disciplinada, en donde un antes, un después y un proceso son necesarios para obtener logros y adquirir competencias, porque se han empleado el análisis y la síntesis, llegando a forjar una mente creativa con gran sentido ético y en donde vierte toda su capacidad y originalidad, dada su singularidad.

\section{La persona desde su autonomía-libertad}

Il est vrai cepandant que la liberté est source vive d'être, et qu'un acte n'est un acte d'homme que s'il transfigure les données les plus rebelles dans la magie de cette spontanéité.... la liberté de l'homme est la liberté d'une personne, et de cette personne, ainsi constituée et située en elle-même, dans le monde et devant les valeurs (Mounier, I995: 7I) $)^{5}$.

4 Rumbo a una integración sistemática del conocimiento. Existen tres conceptos básicos de sistemas: enfoque, inter-trans disciplina y metodología, necesarios para la integración del conocimiento, su balanceo apropiado conduce a la eficaz y eficiente integración del mismo, que contribuye al desarrollo individual humano, social y a la preservación de nuestro entorno natural. Así, se agrupan las características fundamentales de la era de los sistemas. Concepto de Germán Sergio Monroy Alvarado. UAM-X México, marzo 1996.

«Es verdad, sin embargo, que la libertad es fuente viva de ser, y que un acto sólo es un acto humano si trasfigura los hechos más rebeldes en la magia de esta espontaneidad... Sin embargo, la libertad del hombre es la libertad de una persona, y de esta persona, constituida y situada en sí misma de determinada manera, en el mundo y ante los valores» (Mounier, I995: 7I). 
Ser sujeto es ser libre; a través de su libertad el hombre trasciende su necesidad; el hombre libremente puede hacerse libre o puede esclavizarse, optando entre la voluntad de «ser-persona» o renunciando a ello, como lo expresa Mounier, en su tratado del personalismo.

La Libertad es fuente viva de ser, para llegar-a-ser, conforme a su condición ontológica; por eso, es ruptura pero, a la vez, es conquista; es disponibilidad y adhesión en la responsabilidad, actuando con autonomía, como señor de sí y de la historia (León, 2000: 75 y ss.). Conquistar la libertad es realizar el propio yo, siendo realmente lo que se es, conforme a su esencia.

Nuestra libertad es una libertad de ser, de llegar-a-ser, de progresar; nos viene dada por el hecho de haber sido creados a imagen de Dios según el pensamiento cristiano. El hombre libre es el hombre responsable que llega a comprometerse con su propio ser persona. En esta línea de pensamiento, toda persona es una vocación, un llamado para «ser» conforme a su naturaleza; ha de ser el fruto más genuino «del escoger», resultado de la constante iniciativa de una voluntad que progresivamente se va tornando inflexible frente a su propio destino.

La Misión educativa frente a la libertad de la persona no es otra que orientar para que por sí misma descubra su vocación, volviéndose responsable de la propia vida y escogiendo los mejores medios para realizarla, porque ser libre es comprometerse, es responsabilizarse de la formación permanente que debe ir desenvolviendo día a día. Esto supone el ir suscitando valores para crear actitudes acordes con ellos; se necesita de serenidad para la elección; una actitud interna de encuentro consigo mismo y con los otros; es un acto que involucra a la persona en totalidad llevándola a obrar conforme a su ser. La finalidad de la persona es lo infinito y su bien y su gozo se hallan en el intento de alcanzarlo mediante la obra finita, realizada siempre con perspectiva e ilusión.

El concepto de libertad se apoya fundamentalmente en considerarla como base de la actividad humana en sus actos fundamentales: la elección, la aceptación y la iniciativa. Ahí nos jugamos nuestra propia vida. Bien podríamos decir que cada acto de libertad es una pequeña semilla de la cual germinará el fruto de nuestras decisiones, dando origen al gran bosque, liderado por su propio autor, en donde se puede apreciar arte $y$ capacidad para dirigir con prospectiva; uso del conocimiento como poder, empleando las inteligencias múltiples; arte para organizar su propia vida, gracias a la calidad de las metas y a la ejecución estratégica de las mismas.

Dado lo anterior, la libertad es, ante todo, la capacidad para asumir el pleno desarrollo. Esta actitud de discernimiento que se va formando en el estudiante lo lleva a la apertura, a saber escuchar, a analizar la realidad en relación con su posición y la de los otros, para tomar decisiones adecuadas.

La educación es una difícil tarea de equilibrio para que en ese desear que la «persona-sea» no se impongan el egoísmo y las propias conveniencias, gustos e intereses; se busque el equilibrio entre las normas, responsabilidades y se asuma una actitud respetuosa a la libertad del estudiante para que llegue-a-ser lo que debe ser.

En el equilibrio que ha de tenerse frente al binomio autoridad-disciplina, Marie Poussepin, fundadora de la Congregación de Hermanas de la Caridad Dominicas de la Presentación, en sus Reglas Generales pone su acento con verdadero tacto pedagógico: «Sed dulces sin debilidad, firmes sin dureza, graves sin altivez, corregid sin encolerizaros, haceos respetar y amar a un mismo tiempo» (León, 2000: 86). 
Al estar frente al otro, se daría una invocación mutua de actitudes personalizantes. Así, la educación es una «invocación» a la libertad del estudiante para que vaya realizando su proyecto personal de vida en el crecimiento de su autonomía.

\section{La persona en su dimensión relacional de apertura-trascendencia}

L'aspiration trascendante de la personne n'est pas une agitation, mais la négation de soi comme monde clos, suffisant, isolé sur son propre jaillissement. La personne n'est pas l'être, elle est mouvement d'être vers l'être, et elle n'est consistante qu'en l'être qu'elle vise (Mounier, 1995: 79) .

Al tratar el aspecto de la singularidad ya abordábamos la interrelación con el otro, gracias a la apertura que, como ser social, lleva la persona en su misma esencia. La relación personal como elemento constitutivo de la estructura personal del hombre denota la dinámica que posee de autocomunicarse: por naturaleza, la persona es un ser relacional.

El hombre se encuentra como persona en cuanto se autoposee y, a la vez, tiene conciencia de su alteridad. Para llegar al otro, captándole en el valor que posee, sobre todo en el terreno educativo, hay que partir de la propia singularidad, para poder verlo como ese «álter ego», un otro tú con la misma esencia, valores y posibilidades, pero con características personales que se han de captar y respetar.

En palabras de Mounier, la persona solo existe hacia los otros, solo se conoce por los otros, solo se encuentra en los otros (Mounier, 1980). La persona es por naturaleza comunicable y continúa diciendo: «se expone», como la luz, desde su conciencia íntima, con esa presencia secreta que se irradia hacia el universo entero. El encuentro mayor consigo misma se va dando en la medida de la desposesión de su egocentrismo. La riqueza de su ser se manifiesta cuando se despoja de sí misma, del tener; por eso, ante todo hay que «ser».

La capacidad de Apertura se fortalecerá desde las aulas escolares si se orienta para entrar en relación con el conocimiento, como ya lo hemos expuesto; es decir, aprender a aprender, a conocer, aprender a hacer, aprender a vivir juntos, aprender a ser, con todo lo que implica de solidaridad, comunicación y justicia; aprendizajes éstos que se pueden condensar en el aprender a ser, tal como lo enfatiza Mounier.

El hombre se halla bien cuando se da a sí mismo, cuando su adhesión al otro es auténtica y expresa su compromiso mutuo dada su realidad trascendente. Y en el sentido cristiano, al experimentarse recreado por Dios, entra dentro de su plan a través de la comunión y la participación, llegando de repente a un estado superior de vida: la vida en Dios y con Dios; entonces la vida cobra fascinación y plenitud.

En la entrega al otro, a los otros, como experiencia fundamental, gracias a la interpelación: sé conmigo, implícita en el encuentro, es necesidad existencial que se aprende desde el hogar y en los ambientes escolares, mediante los trabajos en equipo, en la realización de proyectos volcados a la realidad para intervenirla y cambiarla en aras de la justicia y dignidad de las personas. Cobra aquí importancia la formación para adquirir competencias ciudadanas, llegando a trabajar de manera constructiva

6 «La aspiración trascendente de la persona no es una agitación, sino la negación de sí como mundo cerrado, suficiente, aislado en su propio surgimiento. La persona no es el ser, es movimiento de ser hacia el ser, y solo es consistente en el ser al que apunta» (Mounier, 1995: 79). 
en y con la sociedad. Es habilitarnos mutuamente para construir realidad, cuidando nuestros entornos y entendiendo un mundo de interdependencia y cambio, necesitado de equilibrio entre ciencia y arte, lógica e imaginación.

Es así como el ser persona caracterizado originariamente por su sentido de don en la apertura debe ir siendo un ser-para-los otros. «La persona es un ser al cual solamente le conviene una sola dimensión: el amor» (Tzitzis, I999: 6I), porque la persona humana tiene la capacidad, al poseer una libertad ontológica, recibida de Dios mismo, de contribuir a la elevación de la humanidad; comporta en sus gérmenes un sentido de justicia trascendente-Dios es justicia- que debe ser expresada en la caridad, anota Tzitzis.

Para un cristiano, «el rostro del hombre se descubre a nosotros, sólo cuando vemos vivir lo humano en el rostro de quien vive todo desde Dios: en Jesús de Nazaret. Y es en Él, en relación amorosa con su Padre, en el Espíritu, cuando más entendemos nuestra esencia personal. Dios-Trino, Dios-Comunidad nos llama también a ser con los otros por Él» (Díaz Granados, 200o: 53). Es así como el Dios de la eternidad se convierte en el Dios del tiempo y de la historia, el Dios que impulsa su política con su pueblo, convirtiéndose para nosotros en el modelo siempre válido del amor.

El impulso a un Ser en plenitud está en esta dimensión de apertura marcada por el sentido de trascendencia, propio del ser humano. Mediante una comunión existencial profunda, la persona penetra en el ámbito de lo supraempírico, en la plenitud de la vida personal, experimentando el llamado personal de una Persona Suprema.

La aspiración trascendente es la negación de sí como mundo cerrado; es ese movimiento de ser, de querer ser, experimentando ser consistente solamente cuando tiende hacia el Ser del cual es imagen: Dios. Ahí está situado su sentido transcendente. Su espíritu siempre emerge, no se satisface con las relaciones que establece, la materia se da por la vida, la vida por el espíritu, el espíritu por Dios, como dice Blondel (I950). La vida del hombre es una noción sensiblemente más rica que su existencia que siempre le estará manifestando su pertenencia al ser; la humanidad de la persona tiende al ser.

El espíritu, situado en el cuerpo y con el cuerpo, formando una unidad personal, aparece como esencia, actualmente finita, pero virtualmente infinita, porque no es otra cosa que la posibilidad, siempre libre, de autorrealizarse mediante la relación esencial con Dios.

La existencia humana, inmersa en el tiempo, está toda por devenir como le es propio de su relación espacio-temporal; éste es un atributo tan característico de la existencia, como la eternidad lo es del Ser. Aquí reside la trascendencia esencial del hombre; sólo al superarse a sí mismo, al salir fuera de sí mismo en la entrega al otro, a Dios, en definitiva, realiza la persona su propia y peculiar «ser sí mismo» como afirma Mounier.

El hombre, que conlleva el ser, es a la vez testimonio del Ser, del cual proviene. En palabras de Schillebeecks (I995), la vida se oculta en el misterio de un Dios personal, realidad que compromete a la persona en su existir y realización de su libertad en orden a la Verdad Absoluta.

Siempre nos encontramos con la realidad más honda de la vida, el amor superando lo finito por la trascendencia. Se puede amar porque el amor no termina en lo finito; está fundado en la relación con el absoluto bien personal sincronizando totalmente con su naturaleza: el Sumo Bien.

Es el amor el que nos coloca en la pista de la interpretación de la dimensión trascendente del hombre porque revela la manera más íntima de ser de la persona. Aquí 
radica la inquietud fundamental del hombre, frente a la finitud de los demás encuentros; su tendencia es superar el horizonte de lo finito como último término de su dimensión trascendente (León, 2000: I24).

Gabriel Marcel (1969), en su Diario Metafísico al hablar de la trascendencia, coloca la disyuntiva de existir definitivamente si damos respuesta al vaLOR con querer y proceder moral, contra el cual ni siquiera prevalecerá la amenaza de la muerte. Al situar a la persona en el misterio del ser, misterio ontológico que se halla enteramente en ella y con el cual está comprometido, experimenta la alegría vinculada al sentimiento de lo inagotable.

La forma suprema y más pura de la veneración religiosa de Dios es el amor personal a Dios, que es Persona, al que se afirma y se ama por razón de sí mismo: por razón de su grandeza y de su belleza, de su sabiduría y de su amor que se hace humildad y anonadamiento para encontrarse con su criatura a la que asume y le da el carácter de hijo, en Jesús de Nazaret (Ef 3, I4-2I). La persona tiene que ir haciendo este recorrido de interiorización para que sus actitudes le permitan elevar los niveles de conciencia, que le garanticen integrar su ser y su quehacer, viviendo con sabiduría, de tal modo que se vayan adquiriendo el autodominio, el esclarecimiento y la serenidad para poder llevar a cabo «el propósito de la vida»: realizarse como persona; para lograrlo, entre otros medios, aclarar conceptos:

> Sobre Dios: la imagen que se tiene de Él y, entonces, penetrar en el conocimiento que nos dio y mostró Jesucristo.

> Sobre sí mismo: ennobleciendo la autoestima mediante la exploración de los talentos que se poseen para aplicarlos al propósito de la vida. Jesús toca lo más íntimo de la persona (comprobarlo en los pasajes del Evangelio sobre la samaritana, la adúltera, sus discípulos, Nicodemo...), trabaja su interior. De ahí, la Ética, la integridad y responsabilidad como principios básicos.

- Sobre el otro: como a un álter ego; con compasión, misericordia y respeto. Trabajando juntos para mejorar el mundo como sujetos de deberes y derechos; sirviéndole desinteresadamente.

> Sobre la Historia: sus raíces, causas, consecuencias, huellas, para proseguirla con responsabilidad, dejando el sello de seres trascendentes, marcados por la inteligencia, la voluntad y la libertad, como realidades específicas del ser-persona.

> Sobre la naturaleza y la realidad en la cual acontece nuestra vida: el mundo; la creación es nuestra hermana, su contacto y estudio nos permitirá comprenderla en todas sus dimensiones despertando nuestra conciencia, para asumirla con responsabilidad, a la vez que nos ayudará a reconectarnos con el Ser. Dios nos habla a través de la realidad y su Palabra; desde el mundo complejo y globalizado del siglo xxI, con sus avances científicos y tecnológicos que encierran un valor aún mayor, al ser puestos al servicio de la humanidad.

La finalidad humana, inscrita en la creación del mundo, se inserta en la misma finalidad del hombre: tiende a Cristo como centro unificado de la Comunidad humana, lo explicita en su libro Marta Díaz Granados (1998).

Ésta es la culminación a que debe llevar todo un proceso educativo centrado en la persona. En los años de educación formal ha de poner las bases para una educación permanente, que se va fortificando y va madurando en medio de la realidad que la 
mediatiza, pero que, a la vez, le interpela constantemente. Será obra de toda la vida; así será capaz de influir en la transformación del mundo, al permanecer abierta a la acción del Espíritu (cfr. Is II, I-9).

Exister, c'est dire oui, c'est accepter, c'est adhérer. Mais si j'accepte tujours, si je ne refuse et ne me refuse jamais, je m'enlise. Exister personnellement, c'est aussi et souvent savoir dire non, protester, s'arrancher... la liberté de l'homme est la liberté d'une personne, et de cette personne, ainsi constituée et située en ell-même, dans le monde et devant les valeurs (Mounier, 1995: 71; 73) 7 .

Desde esta primera aproximación a lo que significa persona humana se derivan importantes implicaciones. En efecto, si lo anteriormente expuesto son las dimensiones de lo personal y si el personalismo es la postura que da primacía a la persona, se pueden considerar tales dimensiones como valores y criterios últimos, tanto para juzgar y valorar como para orientar nuestras acciones y nuestras vidas. Todo aquello que propicie nuestra singularidad, nuestra autonomía, nuestra apertura y nuestro sentido trascendente.

Por consiguiente, hablar del concepto de Persona en educación es definir lo más específico del hombre: lo espiritual, entroncado en su mente y conciencia, con el sentido profundo de la libertad que entraña; de ahí su individualidad e historicidad, de donde surgen grandes planteamientos:

Se está en la existencia para evolucionar y crecer;

$>$ Para descubrir quiénes somos;

> Para transformar el medio que nos rodea de acuerdo con lo que realmente somos.

Grandes maestros espirituales han enseñado que estamos en el mundo para trascender, para adorar a nuestro creador, para valorar la inmensidad de la creación y, ante ella, aprender a ser humildes. Todas estas cosas pueden manifestarse cuando realmente sabemos quiénes somos. Éste es el misterio central de la vida... (Chopra, 2006: 73).

Es el concepto que responde a la cuestión sobre el qué y quién de la existencia, haciendo aparecer los aspectos de subjetividad, identidad y carácter personal que muestran el sí-mismo que conlleva la persona, como unidad en la diversidad; espiritual y material; su sacralidad está en la trascendencia que la orienta; su inteligencia apunta al Infinito; la talla que le mide es su grandeza moral (Tzitzis, 1999: 172).

\section{Bibliografía}

Amengual, Gabriel (2007) Antropología Filosófica. Madrid: Bac.

Aristóteles (2004) La Política. Madrid: Mestas Ediciones.

Blondel, M. (1950) Exigences philosophiques du christianisme.

Chopra, Deepak (2006) La Paz es el Camino. Editorial Norma.

Coreth, Emerich (1964) Metafísica. Barcelona: Ediciones Ariel.

«Existir es decir sí, es aceptar, es adherir. Pero si acepto siempre, si no niego ni me niego jamás, me hundo. Existir personalmente es también y a menudo, decir no, protestar, arrancarse... La libertad del hombre es la libertad de una persona, y de esta persona, constituida y situada en sí misma de determinada manera, en el mundo y ante los valores» (Mounier, I995: 71; 73). 
Cury, Augusto Jorge (2002) El Maestro de los Maestros. Colombia: Ediciones Paulinas.

Descartes, R. (2003) Discurso del método. Estudio preliminar, traducción y notas de E. Bello Reguera. Madrid: Tecnos.

Díaz Granados Santos, Marta, O. P. (1998) El educador dinamizador de la filosofía que orienta la acción educativa. Manizales: Editorial Universidad Católica de Manizales.

Doncell, J. F. (1970) Antropología Filosófica. Buenos Aires: Ediciones Carlos Lohlé.

Freire, Paulo (197I) Pedagogía del Oprimido. Bogotá: Editorial Latinoamericana.

Fromm, Erich (1972) El arte de amar. Barcelona: Edit. Paidós.

Hegel, G. W. F. (2006) Fenomenología del Espíritu. Traducción de Manuel J. Redondo. Pre-Textos.

León Guevara, Judith O. P. (1981) Personalización Liberadora Exigencia Educativa. Envigado. Bogotá: Susaeta Ediciones

León Guevara, Judith O. P. (2000) Fundamentos para una Personalización Liberadora. Manizales: Editorial Universidad Católica de Manizales, sexta edición.

León Guevara, Judith O. P. (200I-2007) La Unidad de Producción de Conocimiento UDPROCO-Una Mediación Pedagógica para la Formación en Educación Superior, tomo I. Bogota, D.C.: Arte Publicaciones y tomo II, 2007, Manizales: Centro Editorial U. Católica de Manizales.

Locke, John (1980) Ensayo sobre el entendimiento bumano, I.2, cap. 27, n. II (pp. 492-493). Madrid: Editora Nacional, vol. I.

Marcel, Gabriel (1969) Diario metafísico. Madrid: Ediciones Guadarrama.

Mounier, Emmanuel (1980) El Personalismo. I2. ${ }^{a}$ edición: Buenos Aires: Editorial Universitaria de Buenos Aires.

Mounier, Emmanuel (1995) Le Personnalisme. i6. edición. Paris: Presses Universitaires de France.

Ostrander, Sheila y otros (1996) Super Aprendizaje 200o. Barcelona: Grijalbo

Pintor Ramos, Antonio (1986) El Humanismo de Max Scheler. Barcelona: Edit. Paidós.

Rogers, Carl (1978) El Proceso de convertirse en persona. Buenos Aires: Editorial Paidós.

Schillebeecks, Edward (1995) Los hombres relato de Dios. Verdad e imagen. Salamanca: Ediciones Sígueme.

Tzitzis, Stamatios (1999) Qu'est - ce que la personne? Paris: Armand Colin. 